\title{
Corruption, Public Expenditure and Human Capital Accumulation
}

\author{
SPYRIDON BOIKOS \\ Laval University *
}

\begin{abstract}
This paper investigates the possible non-linear effect of corruption on human capital accumulation through two channels. The first channel is through the effect of corruption on the public expenditure on education and the second channel is through the effect of corruption on the physical capital investment. Initially, we construct an endogenous twosector growth model with human capital accumulation and we try to explore the impact of corruption on the allocation of public expenditure and therefore on the distribution of human capital across sectors. Then by using a semi-parametric method, we confirm the presence of non-linearities between human capital and corruption.
\end{abstract}

Keywords: Corruption, Public Expenditure, Economic Growth, Human Capital Investment, Semiparametric Estimation

JEL Classifications: D73, H52, J24, O41, O47

\section{$1 \quad$ Introduction}

The topic of corruption has received recently a lot of attention in the economic literature, with some recent surveys on the topic by Svensson (2005), Aidt (2009) and Campos et al. (2010). Corruption is closely related with rent-seeking behavior and the misallocation of talent. According to Murphy et al. (1991), Murphy and Vishny (1993) and Acemoglu and Verdier (1998) in the presence of corruption, investment in the more innovative sectors of the economy is less profitable due to higher transaction costs and this reduces the incentives for investment in R\&D. Furthermore, due to corruption there is misallocation of public resources and in general public expenditures are less efficient, something that may also lead to a

\footnotetext{
* Corresponding Address: Laval University, Department of Economics, Pavillon J.-A.-DeSeve 2116, G1V0A6, Quebec, Canada. E-mail: spyridon.boikos.1@ulaval.ca. I am grateful to seminar participants at the universities of Guelph, Laval and Milan. In particular, I would like to thank Alberto Bucci (University of Milan, Italy), Dimitris Christopoulos (Panteion University of Athens, Greece), Carlos Ordas-Criado (Laval University, Canada), Theodore Palivos (Athens University of Economics and Business, Greece) and Thanasis Stengos (University of Guelph, Canada) for their useful and very insightful comments and suggestions. Errors and omissions are my own responsibility.

(C) 2016 Spyridon Boikos. Licensed under the Creative Commons Attribution - Noncommercial 3.0 Licence (http://creativecommons.org/licenses/by-nc/3.0/. Available at http: //rofea.org.
} 
reduction of investment in physical capital. All the previous arguments shape the general framework which emphasizes the negative effect of corruption on economic growth. In this context important empirical contributions on this area are among others Mauro (1995), Mironov (2005) and Mo (2001). Moreover, McAdam and Rummel (2004) by using nonparametric methods, identify that corruption is highly persistent and that anti-corruption policy should be of a paramount importance. However, there are also arguments supporting the idea that corruption can have a positive effect on economic growth. ${ }^{1}$

The theoretical literature of the corruption and economic growth nexus is very rich. Some papers in that context are that of Sarte (2000), who analyses the effect of bureaucratic corruption on growth. Mauro (2004) shows that the higher the size of corruption the harder it is to eliminate corruption form an economy. A theoretical growth paper with endogenous corruption worth mentioning is that of Barreto (2000), who finds in a neoclassical framework that corruption mainly redistributes income and that this does not necessarily hurt the economy. Blackburn et al. (2006) and Blackburn (2011) show that corruption negatively affects growth because public resources are used in detection mechanisms for corruption reduction and are not used directly for investment in physical capital. Moreover, corruption reduces the quality of public goods.

On an important separate dimension, the evidence at the macro level concerning the role of human capital on economic growth is ambiguous. In studies, such as Barro (1991), Bils and Klenow (2000) and Mankiw et al. (1992), there exists clear positive effect of human capital on the growth of output (GDP). In other studies however, such as Benhabib and Spiegel (1994), Islam (1995), and Lau et al. (1991), human capital has a negligible contribution to economic growth. Kalaitzidakis et al. (2001), using non-parametric techniques, were among the first to search empirically for a non-linear effect of human capital accumulation on economic growth. In our paper, we follow a similar strategy as in Kalaitzidakis et al. (2001), since we establish the existence of non-linear effects of corruption on important components of the formation of human capital accumulation and, hence, economic growth.

Most of the theoretical literature focuses on the impact of corruption on both physical capital investment and misallocation of public expenditure, but not in their subsequent impact on human capital accumulation. One important theoretical paper which takes into account the

\footnotetext{
${ }^{1}$ The papers, which support the optimistic view of corruption, consider corruption as a mechanism which increases efficiency in countries where institutions are not functioning well due to high red tape by reducing barriers for new firms. Recent papers on this direction are those of Aidt et al. (2008) and Ebben and Vaal (2011). Some older papers that are making similar arguments are Leff (1964) and Huntington (1968).
} 


\section{BOIKOS Corruption, Public Expenditure and Human Capital Accumulation}

effect of corruption on human capital accumulation is that of Ehrlich and Lui (1999). They suggest that corruption affects negatively human capital because more time is invested in political capital to improve the bureaucratic power of individuals than on productive education sector. Pecorino (1992) investigates the impact of rent seeking on economic growth in a model with human capital accumulation. Empirical papers of Devarajan et al. (1996) and Ghosh and Gregoriou (2008) justify empirically that public spending on sectors different from education has more positive impact on growth. That may be due to the fact that there may be already too much public investment on education and its marginal effect in that case would be small, or because of the presence of corruption in the education sector. However, in contrast to our model, they do not use human capital accumulation and do not check for the impact of corruption in the allocation of government spending.

The current paper in a simple model with exogenous corruption tries to suggest and check empirically the notion that corruption affects human capital accumulation, differently through different paths, and therefore long run growth. ${ }^{2}$ Corruption affects two important components of human capital: public expenditure devoted to education and the investment on physical capital. The two previous components in turn affect the decision on how much to invest in per capita human capital. The two forces shape the final total effect of corruption on the economy, through human capital accumulation. Therefore corruption and human capital accumulation appear to constitute a non-linear relationship. In this context very little attention has been given to the effect of corruption on human capital accumulation. ${ }^{3}$

The contribution of our paper is that we make two hypotheses on the formation of human capital: firstly, the allocation of public expenditure among different sectors affects the fraction of human capital that is distributed between final output sector and education sector and secondly we assume that the growth rate of physical capital affects negatively human capital accumulation. ${ }^{4}$ Furthermore, we check empirically our specification of human capital and we uncover a non-linear effect of corruption on the two determinants of human capital: public expenditure on education and growth rate of physical capital.

\footnotetext{
${ }^{2}$ Corruption is considered as an exogenous variable in the present study. More specifically, bureaucrats do not appear explicitly in the model. What appears however is the result of bureaucrats' actions which is a specific amount of stolen public resources.

${ }^{3}$ One of the very few attempts is the paper of Rogers (2008) who uses standard OLS regression methods and he investigates the direct effect of corruption on human capital.

${ }^{4}$ According to Aghion and Howitt (2007), technological progress should be distinguished from the physical capital investment. The physical capital investment is just an increase of the physical capital in terms of quantity not of quality. Therefore, the main implication of this assumption is that if more physical capital investment happens then it would be a higher demand for workers with medium or lower level of education which can lead into a runway of individuals from the education system.
} 
Empirically, we try to investigate the presence of non-linear effects of corruption on the two components of human capital. To carry out our empirical analysis we use semiparametric methods which provide the required flexibility at the empirical level. Our results, suggest that public expenditures due to the presence of corruption have a positive but declining effect on human capital accumulation. This may be due to the fact that either corruption cannot distort at the same level the effect of public expenditures on education as it does in other sectors or that because of corruption individuals have an incentive to accumulate more human capital. Furthermore, corruption is detrimental to human capital mainly through the deterioration of physical capital investment, and it seems obvious that the negative effect of corruption through physical capital dominates any possible positive effect through public expenditure on education. ${ }^{5}$

In section 2 we provide the theoretical model. In section 3 we provide the analytical framework needed for the empirical part and in section 4 we provide both a brief exposition of the econometric methods and the empirical results. Finally, in section 5 we conclude.

\section{Theoretical Model}

\subsection{Set up of The Model}

The model is a two sector growth model with endogenous human capital accumulation in the same spirit as in Lucas (1988) and we assume a closed economy with homogeneous agents. In this model we focus on the social planner case because we want to check how the distribution of public resources in the different sectors of the economy, by a benevolent social planner, affects the allocation of human between different sectors in the presence of corruption. ${ }^{6}$ In our economy the total public expenditures are given as: $G_{t}=G_{H t}+G_{Y t}$ where $\left(G_{H t}\right)$ is the public expenditure on education and $\left(G_{Y t}\right)$ is the public expenditure on other activities but mainly on infrastructure, ${ }^{7}$ whereas $s_{H t}=\left(G_{H t} / G_{t}\right)$ and $s_{Y t}=\left(G_{Y t} / G_{t}\right)$ are the shares of public

\footnotetext{
${ }^{5}$ One may argue that the higher the public expenditure on education the more educated can be the population and there exists appropriate environment for research but the opposition to this argument is that corruption does not leave space for the private sector of the economy to innovate since any investment becomes very costly.

${ }^{6}$ In this paper we speak about bureaucratic corruption and not about corruption at political level.

${ }^{7}$ Tanzi and Davoodi (1997) provide empirical evidence that in a corrupted environment the public expenditure on education is high but the public expenditure on operations and maintenance is low which leads into a lower productivity of public capital. Also by looking at the data the countries which belong to above the average level of corruption (the average corruption is 2.22 according to the corruption index) have on average 0.1658 as a share of public expenditure on education where on the contrary countries with low level of corruption have on average 0.1454 as a share of public expenditure on education. This can be due to the fact that the public expenditures for education (mainly salaries for teachers-professors) cannot be used easily by corrupted bureaucrats.
} 


\section{BOIKOS Corruption, Public Expenditure and Human Capital Accumulation}

expenditures on total public expenditures which are used in education and final output respectively. A constraint is: $s_{H t}+s_{Y t}=1$. Corrupted bureaucrats ${ }^{8}$ which are exogenous to the model are able to steal a fraction $(1-\zeta) s_{H t}$ from the education sector and $(1-\delta) s_{Y t}$ from the final output sector with $\delta, \zeta \in(0,1)$. Therefore, after corruption, the public expenditure which is available for the education sector is $\zeta s_{H t}$ and that in the final output sector is $\delta s_{Y t}$. At a more general level of the analysis we assume that the corruption level is different between sectors. $^{9}$ In our economy households take into account the actions of corrupted bureaucrats when they choose how to allocate their human capital but corruption in our model is exogenous and we do not analyze the incentives of bureaucrats to be corrupted and therefore how corruption appeared in the first place. Furthermore, we assume no population growth and as such the aggregate and per capita variables coincide. The fraction of human capital which enters into the education sector is:

$$
u_{1 t}=H_{H t} / H_{t}=f\left(\zeta s_{H t}\right)
$$

The fraction of human capital which enters into the production of final output sector is:

$$
u_{2 t}=H_{Y t} / H_{t}=g\left(\delta s_{Y t}\right)=g\left(\delta\left(1-s_{H t}\right)\right)
$$

According to the equation (1) if more public resources after the effect of corruption on them are attributed to the education sector, the higher will be the quality of education and agents will invest more on education. On the contrary if more public resources after the effect of corruption on them are attributed to the final output sector agents have the incentive to participate on this sector in order to acquire income through their wages. ${ }^{10}$

\footnotetext{
${ }^{8}$ Bureaucrats are useful in providing public goods. We assume that there is no a detection mechanism of corruption, but that corruption exists only exogenously in different levels between countries. We make this assumption because we want to check the effect of corruption on the human capital accumulation and not to lead our analysis on the formation of corruption.

${ }^{9}$ If someone considers the corruption which affects the private sector of the economy not only as an expropriation of public funds which are available for the final output sector but also as a demand for bribes in order firms to operate, then it should be expected. $(1-\zeta)<(1-\delta)$. By looking at the data countries with corruption level above the average face lower physical capital investment than to countries with lower corruption (for highly corrupted countries the average growth rate of physical capital is 0.026 and for the low corrupted countries is 0.028).

${ }^{10}$ For example, according to the data both Greece and Italy face very high corruption above the average which happens in the private sector mainly (the average investment in Greece is 0.021 and in Italy 0.019 , where the average public expenditure in Greece is 0.08 and 0.095 in Italy), even though they both realize high enrollment rates and average years of schooling in their population.
} 
An assumption which guarantees a simultaneous determination of $s_{H t}$ and $\gamma_{t}$ in the balanced growth path equilibrium (BGP) ${ }^{11}$ is that the functions $f\left(\zeta s_{H t}\right)$ and $g\left(\delta\left(1-s_{H t}\right)\right)$ are monotonic and therefore invertible functions, which agrees with the constraint of the allocation of human capital across sectors: $f\left(\zeta s_{H t}\right)+g\left(\delta s_{Y t}\right)=1 .{ }^{12}$ An extra assumption which verifies that the Hamiltonian corresponds to a maximization problem is that the function $f\left(\zeta s_{H t}\right)$ is concave $\left[f "\left(\zeta s_{H t}\right)<0\right]$. This assumption implies that individuals can postpone working by entering into education but this cannot be a situation which lasts for long period, since they need to find a job. From the constraint $f\left(\zeta s_{H t}\right)+g\left(\delta s_{Y t}\right)=1$, the concavity of $f\left(\zeta s_{H t}\right)$ implies that $g\left(\delta s_{Y t}\right)$ is convex. ${ }^{13}$ In order $f\left(\zeta s_{H t}\right)$ to be both concave and monotonic increasing we need to assume that $f\left(\zeta s_{H t}\right)$ is bounded from above, which means: for $\zeta s_{H t} \rightarrow 1 \Rightarrow f(1) \rightarrow f_{\max }<1$ and similarly, $\delta s_{Y t} \rightarrow 1 \Rightarrow g(1) \rightarrow g_{\max }<1$. Moreover, we need $f(0)>0$ and $g(0)>0$ in order always to have allocation of human capital across sectors, even if corruption is zero or at a maximum level or even if an economy has public expenditures or not. It can be shown that an extra necessary condition in order the solution of the Hamiltonian function to correspond to a maximum is that: $(1-\alpha)\left[g^{\prime}\left(\delta\left(1-s_{H t}\right)\right)\right]^{2}>g\left(\delta\left(1-s_{H t}\right)\right) \square g^{\prime \prime}\left(\delta\left(1-s_{H t}\right)\right) .{ }^{14} \quad$ The social planner indirectly affects the distribution of human capital among sectors through the functions $f\left(\zeta s_{H t}\right)$ and $g\left(\delta s_{Y t}\right)$ by deciding on $s_{H t}$ and taking as given the level of corruption. The restrictions for defining well the problem are the followings:

$$
\begin{aligned}
& u_{1 t}+u_{2 t}=1 \Rightarrow u_{2 t}=1-u_{1 t}=1-f\left(\zeta s_{H t}\right) \\
& f\left(\zeta s_{H t}\right)+g\left(\delta s_{Y t}\right)=1 \\
& f\left(\zeta s_{H t}\right), g\left(\delta s_{Y t}\right) \in(0,1)
\end{aligned}
$$

\footnotetext{
${ }^{11}$ The simultaneous determination of the endogenous $s_{H}$ and $\gamma$ is shown in Proposition 4.

${ }^{12}$ These functions $f\left(\zeta s_{H t}\right)$ and $g\left(\delta s_{Y t}\right)$ guarantee always that $u_{1 t}+u_{2 t}=1$. The same can happen even if these two functions are linear and corruption is similar between the two sectors

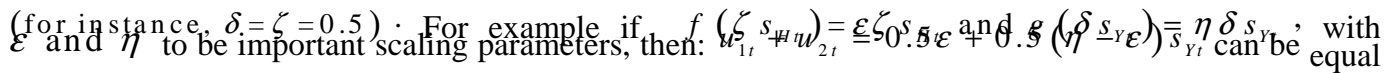
to one for specific values of the scaling parameters. We prefer not to use this notation in order to keep the analysis as much general as we can. Furthermore, with our formulation we can account better for the existence of non-linearities in the relationship between corruption and human capital.

${ }^{13}$ The intuition behind these two assumptions is that the final output sector (private sector of the economy) has the capacity to absorb more individuals in comparison to the education sector.

${ }^{14}$ The above assumptions can be replicated if we consider a logistic functional form for $g\left(\delta s_{Y t}\right)$. The general functional form can be: $g\left(\delta s_{Y t}\right)=\left(1 / 1+\mathrm{e}^{-\delta s_{Y t}}\right)$. In this case it can be easily proved that: $\mathrm{g}^{\prime}>0$, g" $>0, g(0)>0$ and the condition for maximization of the Hamiltonian function is satisfied as well.
} 
BOIKOS Corruption, Public Expenditure and Human Capital Accumulation

$$
f^{\prime}>0, \mathrm{~g}^{\prime}>0 \text { and } f, \mathrm{~g} \text { are bounded and invertible functions }
$$

In this economy the human capital accumulation is given by:

$$
\dot{H}_{t}=\sigma H_{H t}+\varphi \gamma_{K t} H_{t} \Rightarrow \dot{H}_{t}=\sigma\left(f\left(\zeta s_{H t}\right)\right) H_{t}+\varphi \gamma_{K t} H_{t}
$$

with $\left(H_{H t}\right)$ being the level of human capital which is allocated into the education sector and its fraction into that sector is equal to: $H_{H t} / H_{t}=f\left(\zeta s_{H t}\right)$. The parameter $\sigma>0$ represents the productivity of education sector and $\varphi<0$ indicates that the growth rate of physical capital acts as a factor which increases the demand for less educated agents. ${ }^{15}$ The reason we use $\gamma_{K}$ instead of $\dot{K}_{t}$ is in order to have in the steady state both types of public expenditure. Suppose for simplicity that $f\left(\zeta s_{H t}\right) \equiv \varepsilon \zeta s_{H t}$ with $(\varepsilon)$ to be a positive scaling parameter. Then equation (7) can be written as: $\gamma_{H t}=\sigma \varepsilon \zeta s_{H t}+\varphi \dot{K}_{t}$ which is equal to $s_{H t}=\left(\gamma_{H t} / \sigma \varepsilon \zeta\right)-(\varphi / \sigma \varepsilon \zeta) \dot{K}_{t}$, which together with the condition $K_{t}=K(0) e^{\gamma_{K} t}$ gives us: $s_{H t}=\left(\gamma_{H t} / \sigma \varepsilon \zeta\right)-(\varphi / \sigma \varepsilon \zeta) \gamma_{K t} K_{t}$. By differentiating the last expression with respect to time we can get: $d s_{H t} / d t=-(\varphi / \sigma \varepsilon \zeta)\left(\gamma_{K t}\right)^{2} K_{t}$. Then by taking the limit as $t \rightarrow+\infty$ for $\varphi<0$ we get $s_{H}=1$ and for $\varphi>0, s_{H}=0$. We would like to avoid these two extreme cases.

The social planner, by deciding on $s_{H t}$ together with the exogenous level of corruption, can affect the decisions of individuals on how to allocate their human capital between different sectors. Therefore, we consider an economy in which the social planner chooses consumption goods, how much to invest in physical capital and how to allocate public expenditure between sectors by taking into account that this choice affects indirectly the allocation of human capital between sectors. ${ }^{16}$

The production function of the economy at the aggregate level is the following:

$$
Y_{t}=H_{Y t}^{\alpha} K_{t}^{1-\alpha}
$$

\footnotetext{
${ }^{15}$ In this paper, the productivity of human capital is positively related with physical capital by looking at the production function in equation (8). However, we maintain that the accumulation of human capital is negatively related to the physical capital investment because physical capital requires more raw labour than skilled one.

${ }^{16}$ The novelty of this paper is that individuals decide on how to allocate their human capital by taking into account what is the real amount of public resources distributed into different sectors, (this role played by the functions $f\left(\zeta s_{H t}\right)$ and $g\left(\delta s_{Y t}\right)$. In the literature the public expenditure is used as a variable that affects the quality of education sector and not the allocation of human capital in different sectors, see for example Glomm and Kaganovich (2003) among others. With the current formulation implicitly we capture the possibility of people avoiding investing more on education due to a reduction of its quality.
} 
The accumulation of physical capital is:

$$
\dot{K}_{t}=Y_{t}-G_{t}-C_{t}
$$

By following Barro (1990) we consider a balanced budget constraint for government and implement the following condition: $G_{t}=G_{H t}+G_{Y t}=\tau Y_{t} \Rightarrow$

$$
\dot{K}_{t}=(1-\tau) H_{Y t}^{\alpha} K_{t}^{1-\alpha}-C_{t}=(1-\tau)\left[g\left(\delta\left(1-s_{H t}\right)\right)\right]^{\alpha} H_{t}^{\alpha} K_{t}^{1-\alpha}-C_{t}
$$

In this model, we consider that both $G_{Y t}$ and $G_{H t}$ appear implicitly and indirectly on the production function and on the equation of human capital accumulation through the terms $s_{Y t}=G_{Y t} / G_{t}$ and $s_{H t}=G_{H t} / G_{t}$ respectively. This is a simplification assumption which is very useful in order to analyze purely the allocation of human capital among sectors due to the existence of corruption. Moreover, for simplicity we assume a zero depreciation rate for both human and physical capital and we consider the taxation $(\tau)$ to be constant over time. ${ }^{17}$

The instantaneous utility function of the representative agent is: $U\left(C_{t}\right)=\left(C_{t}^{1-\theta}-1\right) /(1-\theta)$, with $\theta>0$ to be the inverse of the inter-temporal elasticity of substitution. So the social planner has to maximize the following problem:

$$
\begin{gathered}
\operatorname{Max}_{\left\{C_{t}, s_{H}, H_{t}, K_{t}\right\}_{t=0}^{+\infty}} U \equiv \int_{0}^{+\infty}\left(\frac{C_{t}^{1-\theta}-1}{1-\theta}\right) e^{-\rho t} d t, \rho>0 ; \theta>0 \\
\text { s.t.: } \dot{H}_{t}=\sigma\left(f\left(\zeta s_{H t}\right)\right) H_{t}+\varphi \gamma_{K t} H_{t}, \quad \sigma>0 ; \quad f \in[0,1], \forall t \\
\dot{K}_{t}=(1-\tau) H_{Y t}^{\alpha} K_{t}^{1-\alpha}-C_{t}=(1-\tau)\left[g\left(\delta\left(1-s_{H t}\right)\right)\right]^{\alpha} H_{t}^{\alpha} K_{t}^{1-\alpha}-C_{t} \quad \forall t
\end{gathered}
$$

along with the transversality conditions (TVC):

\footnotetext{
${ }^{17}$ In this model we are not interested in optimal taxation and we do not make any assumption on possible effects of corruption on taxes. For example an important paper for tax evasion and corruption is that of Been-Lon Chen (2003). More literature on the connection between corruption and tax structure, see among others Fisman and Svensson (2007), Gordon and Li (2009), and Litina and Palivos (2011). Furthermore we avoid from the analysis to use total public expenditures because we are not interested in the optimal public size. For this literature see Johnson et al. (1999) and Tanzi and Davoodi (1997).
} 
BOIKOS Corruption, Public Expenditure and Human Capital Accumulation

$$
\lim _{t \rightarrow \infty} \lambda_{t} H_{t}=0 \text { and } \lim _{t \rightarrow \infty} \mu_{t} K_{t}=0
$$

and the initial conditions: $\mathrm{H}(0)>0$ and $\mathrm{K}(0)>0$ given.

For notational simplicity we avoid the time subscripts and we define the following current value Hamiltonian function that the social planner has to maximize:

$$
\underset{\left\{C, s_{H}, H, K\right\}}{\operatorname{Max}} J=\frac{C^{1-\theta}-1}{1-\theta}+\lambda\left[\left[\sigma\left(f\left(\zeta s_{H}\right)\right)+\varphi \gamma_{K}\right]\right] H+\mu\left[(1-\tau)\left[g\left(\delta\left(1-s_{H}\right)\right)\right]^{\alpha} H^{\alpha} K^{1-\alpha}-C\right]
$$

\section{Definition:}

\section{BALANCED GROWTH PATH (BGP) EQUILIBRIUM}

A Balanced Growth Path (BGP) equilibrium in this economy is a framework where:

i) All time-dependent variables grow at a constant possibly positive exponential rate;

ii) The ratio of the two endogenous state variables, $K_{t} / H_{t}$, remains invariant over time. $^{18}$

\subsection{BGP Analysis}

\section{Proposition 1}

Along the BGP equilibrium, we have:

$$
\gamma=\frac{\sigma\left[f\left(\zeta s_{H}\right)\right]}{1-\varphi} \quad \text { with } \varphi \neq 1 \text { for } \gamma>0
$$

Proof: It follows by considering $\gamma_{H}=\gamma_{K}=\gamma$ in the equation of human capital accumulation.

\footnotetext{
${ }^{18}$ This assumption will lead in the long run in the coexistence of the two forms of capital in the aggregate production function. If for example physical capital grows faster than human capital then in the long run $(t \rightarrow+\infty)$ human capital will become infinitely small relative to physical capital something which against the current empirical evidence which is that both physical capital increases with some fluctuations over time and human capital increases monotonically over time for the most of the countries.
} 
Review of Economic Analysis 8 (2016) 17-45

The next proposition shows the growth rate of the economy described by using all the appropriate FOCS and the result of equation (17).

\section{Proposition 2}

Along the BGP equilibrium, we have:

$$
\gamma_{Y}=\gamma_{C}=\gamma_{H}=\gamma_{K}=\gamma=\frac{\sigma\left(\left[f\left(\zeta s_{H}\right)\right] \theta-1+\varphi\right)}{(1-\varphi) \varphi}+\frac{\rho}{\varphi},
$$

Proof: For the derivations of this expression see Appendix A.

The next proposition shows first of all under what conditions the growth rate from equation (18) is positive and secondly that $\frac{d \gamma}{d \rho}<0, \frac{d \gamma}{d \theta}<0$ and the TVC holds.

\section{Proposition 3}

Along the BGP equilibrium, we have:

For $\quad \gamma>0 ; \frac{d \gamma}{d \rho}<0 \quad$ and $\quad \frac{d \gamma}{d \theta}<0 \quad$, we need $\quad \varphi<0,1-\varphi>f \sqcap \theta \quad$ and $\rho<\frac{\sigma\left(1-\varphi-\left[f\left(\zeta s_{H}\right)\right] \theta\right)}{(1-\varphi)}$. The TVC always holds.

Proof: It follows immediately from Eq. (18). ${ }^{19}$

The parameter restriction of $\varphi<0$, is important for the model, otherwise if $\varphi>0$, then in case that an economy is very impatient (high values $\rho$ of and $\theta$ ), then the growth rate of the economy will be negative, $\downarrow \gamma_{K} \Rightarrow \downarrow \gamma_{H} \Rightarrow \gamma_{Y}<0$.

The next proposition shows that there exists simultaneously an endogenous growth rate $(\gamma)$ and an endogenous share of public expenditure on education $\left(s_{H}\right)$.

\footnotetext{
${ }^{19}$ In this proposition it is shown formally that $\varphi<0$, which supports the idea that the increase of the physical capita investment $\left(\gamma_{K}\right)$ provides extra incentives for individuals to enter into the labour market force which is the same in this model as to allocate more human capital into the final output sector. This result is driven by the model assumption that $\left(K_{t} / H_{t}\right)$ is invariant over time together with the other main assumption that human capital investment is intensive on time and not on output resources which reduce the available income for savings. This assumption can be true in an environment in which public education is the main type of education.
} 
BOIKOS Corruption, Public Expenditure and Human Capital Accumulation

\section{Proposition 4}

Along the BGP equilibrium, we have a simultaneous determined value for $\left(\gamma^{*}\right)$ and for $\left(s_{H}^{*}\right)$ given by:

$$
\left\{\gamma^{*}=\frac{\sigma\left(\left[f\left(\zeta s_{H}^{*}\right)\right] \theta-1+\varphi\right)}{(1-\varphi) \varphi}+\frac{\rho}{\varphi} \text { and }\left(1-s_{H}^{*}\right)=s_{Y}^{*}=\frac{\zeta-f^{-1}\left[\frac{(1-\varphi)\left[\varphi \gamma^{*}+\sigma-\rho\right]}{\sigma \theta}\right]}{\zeta}\right\}
$$

respectively, when we have $\{\sigma>\rho$ and $\rho-\varphi>\sigma\}$, which is always true iff $\varphi<0$, and $\left\{0<\frac{\rho-\sigma}{\varphi}<\gamma\right\}$.

Proof: The proof is in the Appendix A. The important assumption for this proof is that the function $f\left(\zeta s_{H}\right)$ is invertible.

The next proposition shows the effect of corruption in the growth rate of the economy. ${ }^{20}$

\section{Proposition 5}

$\frac{d \gamma}{d \delta}=-\frac{\sigma g^{\prime} \theta s_{Y}}{(1-\varphi) \varphi}>0$, for $s_{Y}^{*} \in(0,1)$ and $s_{Y}^{*}$ to be constant in BGP $; g^{\prime}>0$, and $\varphi<0$, which means $\frac{d \gamma}{d(1-\delta)}<0$, and for $s_{H}^{*} \in(0,1)$ and $s_{H}^{*}$ to be constant in BGP $f^{\prime}>0$, and $\varphi<0$, which means $\frac{d \gamma}{d(1-\zeta)}>0$.

Proof: This result follows from differentiating equation (18) with respect to $\delta$ and $\zeta$ respectively.

First of all, we explain the effect of corruption on economic growth when corruption happens in the public expenditure for the final output sector.

\footnotetext{
${ }^{20}$ Corruption is assumed throughout the paper that can be different between the two sectors and therefore in Proposition 5 we measure the effect of each type of corruption into the growth rate of the economy.
} 
The above analysis indicates that due to the parameter restriction $[\varphi<0]$, the increase of $\gamma_{H}$ is smaller than the decrease of $\gamma_{K}$, and therefore the total effect of corruption on economic growth is negative. The intuition behind this is that when corruption is too high in the final output sector more human capital is allocated to the education sector but the total economy shrinks so much that there is a fall in demand for both high and low skilled workers. Hence, individuals do not have any incentive to postpone working by entering into the education sector. ${ }^{21}$

Now, we provide an explanation about the effect of corruption on economic growth when corruption happens in the public expenditure on education. This can be seen as a situation where corruption reduces the quality of education but the private sector of the economy is not affected and there is demand for labor force educated, or not.

Hence, the lower the corruption in the final output sector, the higher economic growth will be. Furthermore, the higher the corruption in the education sector, the lower the detrimental effect of corruption on economic growth will be.

\section{Analytical Framework}

In this section, we explain what the main equation we estimate is and how it arrives from the theoretical model. Here we introduce a flexible way to allow for a link between corruption and $s_{i t}^{h}$ and $\gamma_{i t}^{k}$ respectively by allowing corruption to be the main determinant of their regression coefficient. In that context we use a flexible semi-parametric econometric model that allows for an unknown smooth coefficient function of corruption for both $s_{i t}^{h}$ and $\gamma_{i t}^{k}$ to capture a potentially different effect of corruption among sectors. The equation we are going to estimate for human capital accumulation is: $\gamma_{i t}^{h}=f\left(\operatorname{corrup}_{i t}\right) s_{i t}^{h}+g\left(\operatorname{corrup}_{i t}\right) \gamma_{i t}^{k}$. where $f\left(\operatorname{corrup}_{i t}\right)$ is the coefficient of $s_{i t}^{h}$ estimated non-parametrically as a function of corruption, and $g\left(\right.$ corrup $\left._{i t}\right)$ is the coefficient of $\gamma_{i t}^{k}$ estimated non-parametrically as a function of corruption. The main point of this specification is that it captures simultaneously the two effects of corruption into the economy: i) the distortion in the allocation of public expenditure (our interest is for public expenditure on education) and ii) the harm of corruption in the physical capital investment since it`s more expensive to accumulate physical capital when corruption is high.

\footnotetext{
${ }^{21}$ The most possible scenario in a situation like this is for individuals to work in the unofficial sector of the economy, but this is something that the model does not intend to capture. An important paper of this direction is the paper of Sarte (2000).
} 
BOIKOS Corruption, Public Expenditure and Human Capital Accumulation

\section{Data, Estimation Method and Empirical Results}

\subsection{Data}

The main equation of interest that we want to estimate is the following:

$\gamma_{i t}^{h}=a_{0}+\sum_{i=1}^{N-1} a_{i} D_{i}+\sum_{j=1}^{Z-1} a_{j} D_{j}+\sum_{t=1}^{T-1} a_{t} D_{t}+\sum_{s=1}^{2} b_{s} X_{s i t}+\theta_{1}\left(\operatorname{corrup}_{i t}\right) \gamma_{i t}^{k}+\theta_{2}\left(\operatorname{corrup}_{i t}\right) s_{i t}^{h}+u_{i t}$

$\left(D_{i}\right)$ is a group dummy separating the sample into OECD and non-OECD countries, and $\left(D_{j}\right)$ is a region dummy in order to capture specific characteristics of sub-Saharan, Latin America and Eastern-European countries which were in transition during the period of our sample. The data are averaged over 5 years for the following periods: 1995-1999, 2000-2004 and 2005-2010. We use time-specific dummy $\left(D_{t}\right)$ in order to avoid business cycle effects. The vector of $\left(X_{\text {sit }}\right)$ consists of two control variables that are used later in order to examine the robustness of our results. These two variables are infant mortality (infmort) and political stability (polstab). The former affects human capital accumulation in the fertility and growth literature and as Gupta et al. (2000) and Rajkumar et al. (2008) argue, it is also affected by corruption due to the low public investment in health services. The latter variable captures the general political framework where corruption can thrive and have an important effect on human capital. ${ }^{22}$ The data for infant mortality (infmort) come from the United Nations dataset (2010) and it is expressed as deaths per 1000 births. The data for political stability (polstab) come from the work of Kaufmann et al. (2010). ${ }^{23}$

As it was mentioned earlier the growth rate of physical capital $\left(\gamma_{i t}^{k}\right)$ or alternatively physical capital investment is worsened by corruption and similarly is the public expenditure on education as a share of total public expenditures $\left(s_{i t}^{h}\right) .{ }^{24}$ Our main goal is to check the two effects of corruption through the two variables $\left(\gamma_{i t}^{k}\right)$ and $\left(s_{i t}^{h}\right)$ on human capital accumulation simultaneously by allowing these effects to be non-linear and variable over time and for different group of countries. The two unknown functions $\theta_{1}\left(\right.$ corrup $\left._{i t}\right)$ and $\theta_{2}\left(\right.$ corrup $\left._{i t}\right)$ depend on the level of corruption and are estimated by a smooth coefficient semi-parametric model. ${ }^{25}$ The difference of this method with OLS in which corruption affects directly and linearly human capital accumulation is that now we assume that both of the coefficients of $\left(\gamma_{i t}^{k}\right)$ and $\left(s_{i t}^{h}\right)$ vary directly with the level of corruption. In that way, since countries have

\footnotetext{
${ }^{22}$ Mo (2001) finds that in countries with high corruption there exists higher political instability. The index of political stability has been used as a control variable of corruption by Bjørnskov (2003).

${ }^{23}$ The higher values of this index correspond to less political instability.

${ }^{24}$ For the negative impact of corruption on physical capital investment see the paper of Mauro (1995).

${ }^{25}$ For details of the method for the smooth coefficient see Fan (1992) and Fan and Zhang (1999), Li et al (2002) and Mamuneas et al. (2006) among others.
} 
different levels of corruption it is expected that the effect of $\left(\gamma_{i t}^{k}\right)$ and $\left(s_{i t}^{h}\right)$ not to be constant across countries and time.

Other data-related points that we want to stress are: First of all, the data for public expenditure on education as a share of total public expenditures come from the United Nations dataset (2010). This variable includes government spending on educational institutions (both public and private), educational administration as well as subsidies for private entities. It is expressed as a percentage. The variable of the growth rate of physical capital $\left(\gamma_{i t}^{k}\right)$ is constructed by using data from Heston et al. (2011). ${ }^{26}$ Finally the data for corruption are obtained from the database of Kaufmann et al. (2010). This variable is defined in such a way as to capture the perceptions of the extent to which public power is exercised for private gain. The original scores range from -2.5 to 2.5 , with higher values corresponding to better outcome. ${ }^{27}$ For human capital accumulation $\left(\gamma_{i t}^{h}\right)$, which is the dependent variable, we use enrollment rates for population aged between 25 and 65 years. The data for this variable come from the Barro-Lee (2010) dataset. The Barro-Lee (2010) dataset has been extensively used in recent years and as such allows us to make direct comparisons with other empirical studies that explore the role of human capital in economic growth. ${ }^{28}$

Finally, due to the possible existence of endogeneity bias which stems from the fact that corruption may relate to human capital in a two-way causality pattern, we also use an instrumental variable approach. Aidt et al. (2008) used the index of voice and accountability (voaac) as an instrument of corruption, variable which is also obtained from the Kaufmann et al. (2010) dataset. Voice and accountability captures perceptions of the extent to which a

26 For the construction of $\gamma_{i t}^{k}=\left(k_{t+1}-k_{t}\right) / k_{t}$, we have used the following formula: $k_{i, t}=k_{i, t-1}(1-\delta)+I_{i, t}$. We have set $\delta=0.06$ which is standard in the literature. The initial value for physical capital has been constructed by $k_{i, t_{0}}=Y_{i, t_{0}} / \alpha$, where $\alpha$ takes the value 2 but we have tried different values around 2 and the results are the same and available upon request. $I_{i, t}$ is the total investment at 2005 constant prices, and $Y_{i, t}$ is the real GDP (Laspeyres), at 2005 constant prices. We have also used data for population in thousands from the same data base. Then we average the constructed series of $\gamma_{i t}^{k}$ in the following intervals: 1995-1999, 2000-2004 and 2005-2010.

${ }^{27}$ In order higher values of the index to represent higher corruption we have transformed the data according to the following formula: corruption=2.5-corruption [Index].

${ }^{28}$ We use total human capital, which is the sum of primary, secondary and higher education. This is done for two major reasons. Firstly, non-OECD countries exhibit very small participation rates at higher levels of education. Finally, because in every country participation at primary and secondary level of education is a necessary requirement in order for people to proceed into higher levels of schooling, we believe it is preferable to include also primary and secondary education in our measure of human capital. We have estimated our results for different categories of human capital and the non-linearities still appear and are even stronger in the tertiary level of education. These results are not presented here but are available upon request. Moreover, according to de la Fuente and Domenech (2006), the stock measure of human capital (total mean years of schooling data) suffer from serious measurement error problems, something that would be exacerbated if we were to obtain growth rates from differencing the stock series. Hence, instead of measuring human capital accumulation in growth rates as it is the case for per-capita income, we prefer to use enrollment rates instead. 


\section{BOIKOS Corruption, Public Expenditure and Human Capital Accumulation}

country's citizens are able to participate in selecting their government, as well as freedom of expression, freedom of association and a free press. The higher the value of this index, the higher is the quality of institutions. We first proceed to perform a test of endogeneity, ${ }^{29}$ and we do not find any evidence for its presence. However, we still proceed to follow a two stage least squares approach using the instrument mentioned above in order to compare the results with the case when we ignore the possibility of endogeneity. The first stage in the two stage approach that uses the following equation

$$
\operatorname{corrup}_{i t}=f\left(D_{i}, D_{j}, D_{t}, \gamma_{i t}^{k}, s_{i t}^{h}, \operatorname{voacc}_{i t}\right)
$$

This is an OLS regression which includes all the exogenous variables and dummies plus the instrument which is the variable of voice and accountability (voacc). Then this regression provides us with fitted values for corruption (corrup) which is the new index that we can use now for corruption in the second stage of the analysis. We will then compare the results from the two approaches, using corrupt and corrup to see how the results differ, if they differ at all. Given that our test failed to detect the presence of endogeneity we expect that the two sets of results will not differ by much

Now we provide a quick exposition of the semi-parametric method of smooth coefficients. Equation (20) in a more compact form becomes:

$$
\gamma_{i t}^{h}=\Psi_{i t} \beta+\theta_{1}\left(\operatorname{corrup}_{i t}\right) \gamma_{i t}^{k}+\theta_{2}\left(\operatorname{corrup}_{i t}\right) s_{i t}^{h}+u_{i t}
$$

where $\Psi_{i t}=\left(D_{i}, D_{j}, D_{t}, X_{\text {sit }}\right), X_{\text {sit }}$ is the vector of the two control variables (polstab ,infmort) which are used for robustness check, and the error term satisfies $E\left(u_{i t} \mid \Psi_{i t}, \operatorname{corrup}_{i t}, \gamma_{i t}^{k}, s_{i t}^{h}\right)=0$. We define $z_{i, t}=\left(\gamma_{i t}^{k}, s_{i t}^{h}\right) \quad$ and $v\left(\operatorname{corrup}_{i t}\right)=\left[\theta_{1}\left(\operatorname{corrup}_{i t}\right), \theta_{2}\left(\operatorname{corrup}_{i t}\right)\right]$. The most important is to estimate $\theta_{1}\left(\operatorname{corrup}_{i t}\right)$ and $\theta_{2}\left(\operatorname{corrup}_{i t}\right)$. In the first step the variables of the linear part are projected off the other variables to produce the new redefined variables and then this leads to the usual local least square method but the choice of the Kernel function is determined by the variable of

\footnotetext{
${ }^{29}$ The Prob>chi2 value of Durbin-Wu-Hausmann test for endogeneity is 0.3724 which means that the initial hypothesis for the absence of correlation between "corruption" and the error term is not rejected, which means that there is no endogeneity bias of corruption. For the Durbin-Wu-Hausmann test for endogeneity see Davidson and MacKinnon (1993).
} 
Review of Economic Analysis 8 (2016) 17-45

Table 1: Summary Statistics

\begin{tabular}{|l|c|c|c|c|}
\hline \multicolumn{1}{|c|}{ Variable } & Mean & $\begin{array}{c}\text { Std. } \\
\text { Deviation }\end{array}$ & Minimum & Maximum \\
\hline \hline Enrollment on Education & 0.814791 & 0.2195798 & 0.169 & 1 \\
\hline $\begin{array}{l}\text { Public Expenditure on } \\
\text { Education }\end{array}$ & 0.156871 & 0.049196 & 0.064158 & 0.346889 \\
\hline Physical Capital Investment & 0.027337 & 0.028283 & -0.045330 & 0.141158 \\
\hline Corruption & 2.222165 & 1.049657 & -0.0101107 & 3.882736 \\
\hline Voice and Accountability & 0.240575 & 0.934729 & -1.802832 & 1.65263 \\
\hline Political Stability. & 0.049254 & 0.904495 & -2.351705 & 1.630576 \\
\hline
\end{tabular}

corruption $\left(\operatorname{corrup}_{i t}\right):\left(\gamma_{i t}^{h}\right)^{*}=v\left(\operatorname{corrup}_{i t}\right) z_{i t}^{*}+u_{i, t}^{*}$. Once $v\left(\operatorname{corrup}_{i t}\right)$ is estimated we project back to redefine $\left(\gamma_{i t}^{h}\right)$ and we run a linear regression to estimate $\beta$. It is a generalized method of varying coefficient models and it is based on local polynomial regression. ${ }^{30}$

We use a standard multivariate kernel density estimator with Gaussian kernel and the rule of thumb suggested by Silverman (1986) as the choice of the bandwidth. The non-parametric element of equation (22) will be examined graphically. Finally, we have performed the Hsiao et al. (2007) test in order to check if the linear model is well specified or alternatively to use a more flexible non-parametric model such as the smooth coefficient method described above. In Table 1 above are the summary statistics for the variables we use and in Appendix B is the list of countries.

\subsection{Empirical Results}

In column A of Table 2, there are the OLS results when we use the corruption index directly without the use of any control variable. From this table we observe that all the main variables of interest enter negatively and corruption moreover is statistically significant using robust standard errors. ${ }^{31}$ In column B of Table 2, we use the new index of corruption from the first

\footnotetext{
${ }^{30}$ For taking into account the equivalence between the smooth coefficient method and the local polynomial method see among others, Stone (1977), Fan (1992), and Gozalo and Linton (2000).

${ }^{31}$ In the paper of Lin (1998), someone can find a theoretical justification how an increase in public expenditure on education can lead into a reduction in the incentive of individual to accumulate human capital.
} 
BOIKOS Corruption, Public Expenditure and Human Capital Accumulation

Table 2: Empirical Results

\begin{tabular}{|c|c|c|c|}
\hline & OLS & OLS & OLS \\
\hline Variables & (A) & (B) & (C) \\
\hline constant & $\begin{array}{c}1.067 * * * \\
(0.052)\end{array}$ & $\begin{array}{c}1.149 * * * \\
(0.070)\end{array}$ & $\begin{array}{c}1.065^{* * *} \\
(0.042)\end{array}$ \\
\hline oecd & $\begin{array}{c}0.036 \\
(0.021) \\
\end{array}$ & $\begin{array}{c}0.001 \\
(0.032) \\
\end{array}$ & $\begin{array}{c}0.024 \\
(0.013)\end{array}$ \\
\hline la & $\begin{array}{c}0.148 * * * \\
(0.024)\end{array}$ & $\begin{array}{c}0.143^{* * *} \\
(0.024)\end{array}$ & $\begin{array}{c}0.106 * * * \\
(0.020)\end{array}$ \\
\hline af & $\begin{array}{c}-0.136 * * * \\
(0.040)\end{array}$ & $\begin{array}{c}-0.136^{* * *} \\
(0.043)\end{array}$ & $\begin{array}{c}0.153^{* * *} \\
(0.042)\end{array}$ \\
\hline $\operatorname{tran}$ & $\begin{array}{c}0.169 * * * \\
(0.022)\end{array}$ & $\begin{array}{c}0.123^{* * *} \\
(0.022)\end{array}$ & $\begin{array}{c}0.053^{* * *} \\
(0.021)\end{array}$ \\
\hline d00 & $\begin{array}{c}-0.082^{* *} \\
(0.022)\end{array}$ & $\begin{array}{c}-0.084^{* * *} \\
(0.022)\end{array}$ & $\begin{array}{l}-0.019 \\
(0.020)\end{array}$ \\
\hline d05 & $\begin{array}{c}-0.036 \\
(0.021) \\
\end{array}$ & $\begin{array}{c}-0.037 \\
(0.022) \\
\end{array}$ & $\begin{array}{l}-0.013 \\
(0.018)\end{array}$ \\
\hline pubexp & $\begin{array}{c}-0.068 \\
(0.259) \\
\end{array}$ & $\begin{array}{c}-0.171 \\
(0.284) \\
\end{array}$ & $\begin{array}{l}-0.305 \\
(0.193) \\
\end{array}$ \\
\hline gk & $\begin{array}{c}-0.777^{*} \\
(0.398)\end{array}$ & $\begin{array}{c}-0.911 * * * \\
(0.405)\end{array}$ & $\begin{array}{c}-1.060^{* * *} \\
(0.411) \\
\end{array}$ \\
\hline corruption & $\begin{array}{c}-0.096 * * * \\
(0.012)\end{array}$ & $\begin{array}{c}-0.116^{* * *} \\
(0.020)\end{array}$ & $\begin{array}{c}-0.012 \\
(0.013)\end{array}$ \\
\hline polstab & - & - & $\begin{array}{c}-0.012 \\
(0.015)\end{array}$ \\
\hline infmort & - & - & $\begin{array}{c}-0.006 * * * \\
(0.000)\end{array}$ \\
\hline R2/R2adj. & $58.15 / 56.54$ & $54.25 / 52.49$ & 73.08/71.81 \\
\hline Observations & 244 & 244 & 244 \\
\hline F-test & $36.13^{* * *}$ & $30.38 * * *$ & $57.27 * * *$ \\
\hline Heteroskedasticity & $105.13^{* * *}$ & $94.33^{* * *}$ & $136.91 * * *$ \\
\hline $\mathrm{P}($ Specific. $)$ & $2.22 \mathrm{e}-16^{* * *}$ & 2.22e-16*** & $2.22 \mathrm{e}-16^{* * *}$ \\
\hline
\end{tabular}

Notes: $* * *, * *$ and $*$ denote the $1 \%, 5 \%$ and $10 \%$ significance level. Heteroskedasticity is present by conducting Breusch-Pagan test. In the parentheses are the robust standard errors. Pubexp is the public expenditure on education as a share of total public expenditure, and gk is the growth rate of physical capital. $\mathrm{P}$ (Specific) shows the p-values if the null of the parametric linear OLS is correctly specified in comparison to a fully non-parametric model, using the Hsiao et al. (2007) test for continuous and discrete data models after 399 Boostrap replications.

stage in order to compare these results with those of using the corruption index directly. The results are qualitative similar with those in column A. Finally, in column C of Table 2, there 
are the results with the inclusion of the two control variables (political stability and infant mortality). The results are quantitatively similar both in OLS and in the semi-parametric framework. 32 Moreover, the results of Hsiao et al. (2007) test suggest that the linear specification is rejected.

In order to see the smooth coefficient semi-parametric results, we proceed to the graphical analysis. According to Figure 1, in low levels of corruption where the more developed countries belong, a marginal increase of corruption leads into a positive effect of public expenditure as a share of total public expenditure $\left(s_{i t}^{h}\right)$ on human capital accumulation. In general the impact of public expenditure on education is positive but decreasing for high levels of corruption. A possible explanation is that when corruption is small a further increase of it will not prevent individuals from acquiring education if the private sector is not affected by corruption. On the contrary if corruption increases too much then the effect of it on the quality of education is big enough in order the individuals to lose their incentives to invest on education.

In the case where we check for the impact of physical capital growth $\left(\gamma_{i t}^{k}\right)$ on human capital accumulation, Figure 2 still suggests the presence of a non-linear relationship. In low levels of corruption, where countries are more developed, an increase of corruption has negative but small impact on the coefficient of $\gamma_{i t}^{k}$ on human capital accumulation. However, for higher levels of corruption the impact of $\gamma_{i t}^{k}$ on human capital investment is negative and more severe. Figure 3 and Figure 4 present the smooth coefficient semi-parametric results when we use the instrumented index of corruption. ${ }^{33}$ The main conclusion from the econometric analysis is that the impact of corruption on human capital is smaller through its effect on the public expenditure on education than through its effect on the physical capital investment something which consistent with the model and gives rise into the importance of private sector.

\footnotetext{
${ }^{32}$ Even if the variable of political stability is not statistically significant it is important to mention that by including this variable as a control variable the non-linearities are prevalent but in countries with high corruption and high political instability the negative effect of public expenditure on education is more severe. The semi-parametric results for the control variables are not presented here but are available upon request.

${ }^{33}$ From a direct comparison of Figure 3 and 4 with Figure 1 and 2 respectively, it is easily observed that the results do not change when we have instrumented for corruption.
} 
BOIKOS Corruption, Public Expenditure and Human Capital Accumulation

Figure 1: The Marginal Effect of Public Expenditure on Education on Human Capital Accumulation

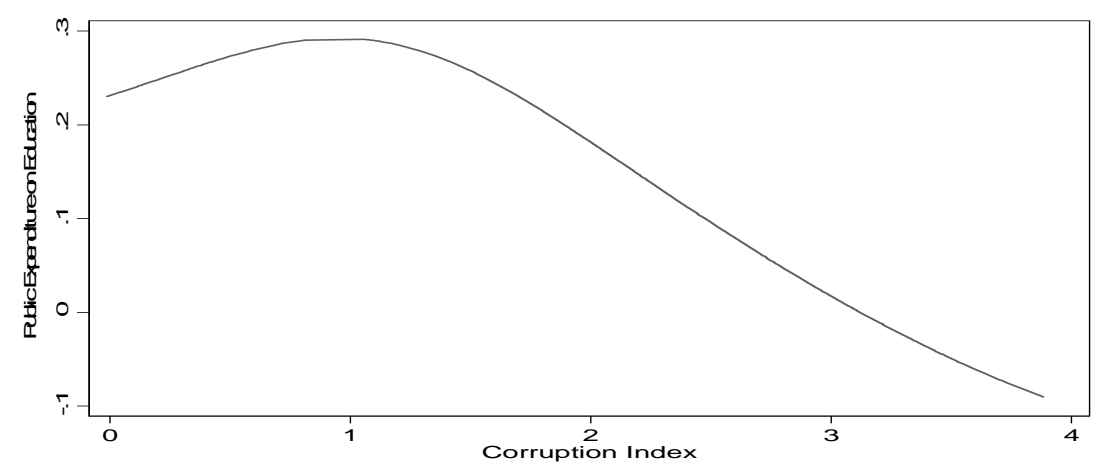

Figure 2: The Marginal Effect of the Growth rate of Physical Capital on Human Capital Accumulation

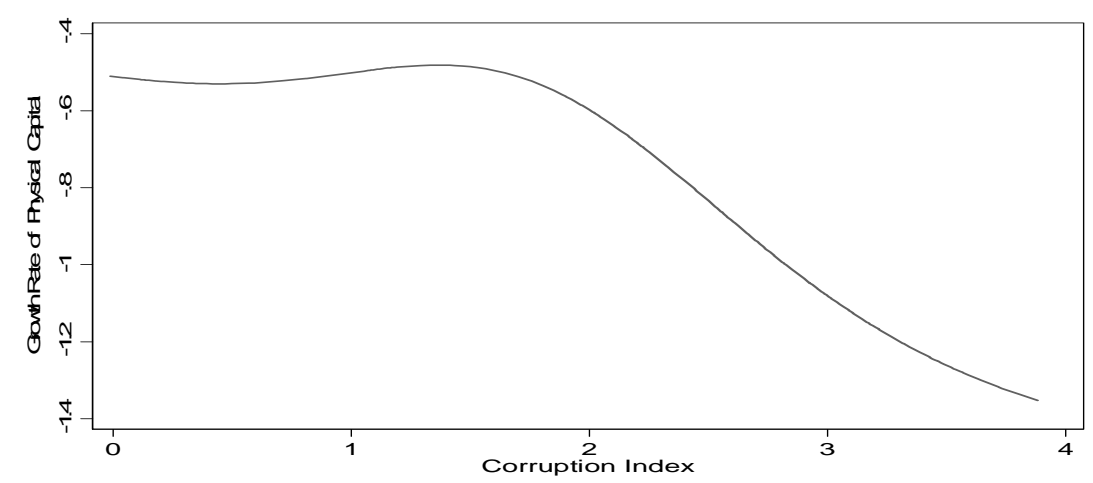

Figure 3: The Marginal Effect of Public Expenditure on Education on Human Capital Accumulation with Instrumented Corruption

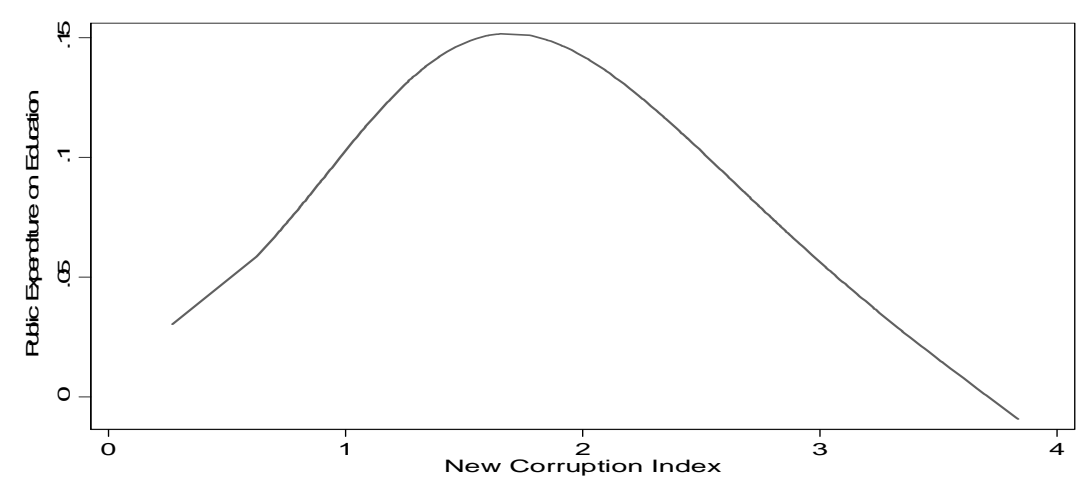


Figure 4: The Marginal Effect of the Growth rate of Physical Capital on Human Capital Accumulation with Instrumented Corruption

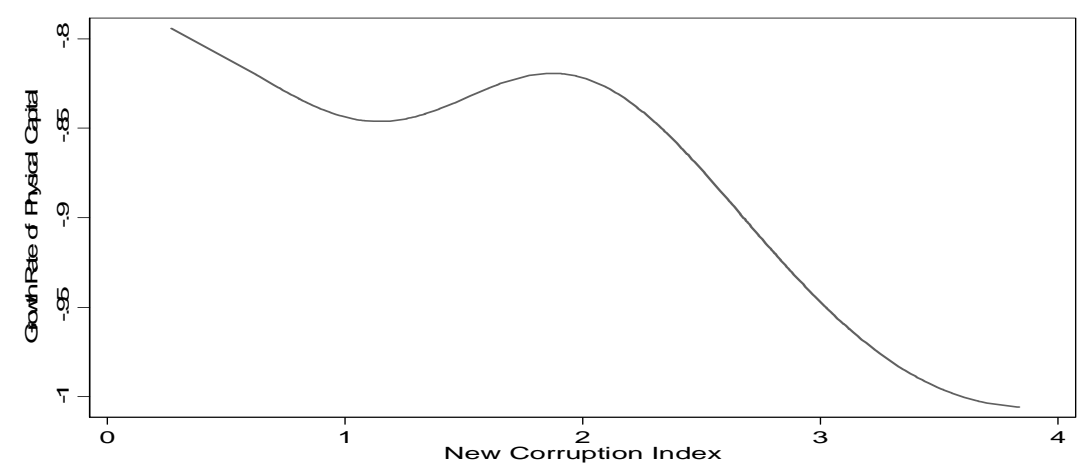

\section{Summary and Conclusions}

In this paper we propose an endogenous growth model where corruption, which is considered as an exogenous variable, can potentially reduce public resources for the different sectors of the economy. This creates a distortion in the allocation of human capital across sectors since one of the main assumptions of our model is that individuals decide on how to allocate their human capital between sectors by considering the net (from corruption) amount of public resources. At the same time another important assumption is that the higher is the investment on physical capital, which is different from technological progress, the higher is the demand for individuals with less human capital, and therefore physical capital investment reduces the investment on education. If corruption affects mainly public expenditure on education then the private sector of economy grows and offset the possible negative effects of corruption on the accumulation of human capital. On the contrary, if corruption affects mainly the private sector of the economy, individuals can postpone participating on the labor force by investing on more education but since there is low demand both for high and low level of human capital then the growth rate of the economy is going to fall.

In the empirical section of the paper we use a semi-parametric smooth coefficient model in order to capture possible differential effect of corruption on the important elements of human capital. The empirical results suggest the existence of non-linearities between corruption and human capital accumulation. More specifically, corruption has a declining but positive effect on the coefficient of the public expenditure on education, but it has mainly a negative effect on the coefficient of physical capital. This intuitively means that even if physical capital investment has by itself a negative effect on human capital due to corruption this effect becomes more severe because the economy shrinks too much and there are no incentives to invest on education anymore. 


\section{BOIKOS Corruption, Public Expenditure and Human Capital Accumulation}

To conclude, corruption has negative impact on human capital accumulation. However, as a result even if the investment on physical capital does not stimulate incentives for more education, corruption should be confronted, otherwise there is a reduction both on human and physical capital accumulation which will affect negatively economic growth. From a policy perspective achieving a higher score in educational attainment does not translate always into higher growth if corruption is a dominant practice in the economy. These results suggest that it would be of a paramount importance for governments to establish policy practices that reduce corruption in the first place before attaining higher standards in other wellbeing measurements such as education.

\section{Appendix A: Equations (17) - (19)}

The current value Hamiltonian is:

$$
J=\frac{C^{1-\theta}-1}{1-\theta}+\lambda\left[\sigma f\left(\zeta s_{H}\right)+\varphi \gamma_{K}\right] H+\mu\left[(1-\tau)\left[g\left(\delta\left(1-s_{H}\right)\right)\right]^{\alpha} H^{\alpha} K^{1-\alpha}-C\right]
$$

In the Hamiltonian function written above $s_{H}$ and $\mathrm{C}$ are the control variables and $H$ and $\mathrm{K}$ are the state variables. The necessary first order conditions read as:

$$
\begin{gathered}
\frac{\partial J}{\partial C}=0 \Leftrightarrow C^{-\theta}=\mu \Rightarrow \frac{\dot{C}}{C}=-\frac{1}{\theta} \frac{\dot{\mu}}{\mu} \\
\frac{\partial J}{\partial s_{H}}=0 \Leftrightarrow \\
\Leftrightarrow \lambda \sigma\left\{f\left(\zeta s_{H}\right)\right\}^{\prime} \zeta \mathrm{H}=\mu \alpha(1-\tau)\left[g\left(\delta\left(1-s_{H}\right)\right)\right]^{\alpha-1}\left\{g\left(\delta\left(1-s_{H}\right)\right)\right\}^{\prime} \delta H^{\alpha} K^{1-\alpha} \\
\dot{\mu}=\mu \rho-\frac{\partial J}{\partial K}=\mu \rho-\mu(1-\tau)(1-\alpha)\left[g\left(\delta\left(1-s_{H}\right)\right)\right]^{\alpha} H^{\alpha} K^{-\alpha} \\
\dot{\lambda}=\lambda \rho-\frac{\partial J}{\partial H}=\lambda \rho-\lambda\left[\sigma\left[f\left(\zeta s_{H}\right)\right]+\varphi \gamma_{K}\right]-\mu \alpha(1-\tau)\left[g\left(\delta\left(1-s_{H}\right)\right)\right]^{\alpha} H^{\alpha-1} K^{1-\alpha}
\end{gathered}
$$

Divide (A3) with $\mu$ :

$$
\frac{\dot{\mu}}{\mu}=\rho-(1-\tau)(1-\alpha)\left[g\left(\delta\left(1-s_{H}\right)\right)\right]^{\alpha} H^{\alpha} K^{-\alpha}
$$


With $g\left(\delta\left(1-s_{H}\right)\right)$ to be constant in BGP in order $\frac{\dot{\mu}}{\mu}$ to be constant as well in BGP, we need:

$$
\frac{\dot{K}}{K}=\frac{\dot{H}}{H}=\gamma
$$

Divide (A4) with $\lambda$ :

$$
\frac{\dot{\lambda}}{\lambda}=\rho-\left[\sigma\left[f\left(\zeta s_{H}\right)\right]+\varphi \gamma_{K}\right]-\frac{\mu}{\lambda} \alpha(1-\tau)\left[g\left(\delta\left(1-s_{H}\right)\right)\right]^{\alpha} H^{\alpha-1} K^{1-\alpha}
$$

Log-linearize and differentiate (A2) with respect to time: $\frac{\dot{\lambda}}{\lambda}+\frac{\dot{H}}{H}=\frac{\dot{\mu}}{\mu}+\alpha \frac{\dot{H}}{H}+(1-\alpha) \frac{\dot{K}}{K}$ and, using (A3'’):

$$
\frac{\dot{\lambda}}{\lambda}=\frac{\dot{\mu}}{\mu}
$$

We solve (A2) with respect to $\frac{\mu}{\lambda}$ :

$$
\frac{\mu}{\lambda}=\frac{\sigma\left\{f\left(\zeta s_{H}\right)\right\} ' \zeta}{\alpha(1-\tau)\left[g\left(\delta\left(1-s_{H}\right)\right)\right]^{\alpha-1}\left\{g\left(\delta\left(1-s_{H}\right)\right)\right\}^{\prime} \delta H^{\alpha-1} K^{1-\alpha}}
$$

By replacing (A2’') into (A4') we get, after some algebra:

$$
\frac{\dot{\lambda}}{\lambda}=\rho-\left[\sigma\left[f\left(\zeta s_{H}\right)\right]+\varphi \gamma_{K}\right]-\sigma\left[g\left(\delta\left(1-s_{H}\right)\right)\right]
$$

which is constant in BGP.

We then equate (A4', ) with (A3') and solve with respect to $\left(\frac{\left[g\left(\delta\left(1-s_{H}\right)\right)\right] H}{K}\right)^{\alpha}$ : 
BOIKOS Corruption, Public Expenditure and Human Capital Accumulation

$$
\left(\frac{\left[g\left(\delta\left(1-s_{H}\right)\right)\right] H}{K}\right)^{\alpha}=\frac{\sigma\left\{f\left(\zeta s_{H}\right)+g\left(\delta\left(1-s_{H}\right)\right)\right\}+\varphi \gamma_{K}}{(1-\alpha)(1-\tau)}=\frac{\sigma+\varphi \gamma_{K}}{(1-\alpha)(1-\tau)}
$$

since $f\left(\zeta s_{H}\right)+g\left(\delta\left(1-s_{H}\right)\right)=1$ by definition.

From the constraint of human capital and (A3’') we get:

$$
\gamma=\frac{\sigma\left[f\left(\zeta s_{H}\right)\right]}{1-\varphi} \text { with } \varphi \neq 1 \text { and } \varphi<1 \text {, for } \gamma>0
$$

From the definition of BGP and from (A3’') together with (A6), $\frac{\dot{K}}{K}=\gamma$ is constant iff:

$$
\frac{\dot{C}}{C}=\frac{\dot{K}}{K}=\frac{\dot{H}}{H}=\gamma
$$

By inserting (A3’) into (A1), equating the resulting expression with (A6) and then solving with respect to $\left(\frac{\left[g\left(\delta\left(1-s_{H}\right)\right)\right] H}{K}\right)^{\alpha}$, we get:

$$
\left(\frac{\left[g\left(\delta\left(1-s_{H}\right)\right)\right] H}{K}\right)^{\alpha}=\frac{\sigma\left[f\left(\zeta s_{H}\right)\right] \theta+\rho(1-\varphi)}{(1-\varphi)(1-\tau)(1-\alpha)}
$$

Then by equating expression (A5) with (A8) we get:

$$
\gamma=\frac{\sigma\left(\left[f\left(\zeta s_{H}\right)\right] \theta-1+\varphi\right)}{(1-\varphi) \varphi}+\frac{\rho}{\varphi}
$$

In order for $\frac{d \gamma}{d \rho}<0$ and $\frac{d \gamma}{d \theta}<0$ we need $\varphi<0$ and for $\frac{d \gamma}{d \sigma}>0$ we need $1-\varphi>\theta \square f\left(\zeta s_{H}\right)$ and for $\gamma>0$ we need $\rho<\sigma \frac{\left(1-\varphi-\left[f\left(\zeta s_{H}\right)\right] \theta\right)}{(1-\varphi)}$.

We now check the two transversality conditions: $\lim _{t \rightarrow \infty} \lambda_{t} H_{t}=0$ and $\lim _{t \rightarrow \infty} \mu_{t} K_{t}=0$. Because of (A2') and (A7) if the transversality condition holds for the one state variable it holds for the other as well. 
Review of Economic Analysis 8 (2016) 17-45

$$
\lim _{t \rightarrow \infty} e^{-\rho t} \lambda_{t} H_{t}=\lambda(0) H(0) \lim _{t \rightarrow \infty} e^{\left(-\rho+\frac{\dot{\lambda}}{\lambda}+\frac{\dot{H}}{H}\right) t}=\lambda(0) H(0) \lim _{t \rightarrow \infty} e^{\left(-\rho+\frac{\dot{\lambda}}{\lambda}+\gamma\right) t}
$$

By replacing into the previous expression (A4'”), $\sigma\left[f\left(\zeta s_{H}\right)\right]+\varphi \gamma=\gamma$ from(A6) and the constraint $f\left(\zeta s_{H}\right)+g\left(\delta\left(1-s_{H}\right)\right)=1$, we have:

$$
\lim _{t \rightarrow \infty} e^{-\rho t} \lambda_{t} H_{t}=\lambda(0) H(0) \lim _{t \rightarrow \infty} e^{\left(-\rho+\frac{\dot{\lambda}}{\lambda}+\frac{\dot{H}}{H}\right) t}=\lambda(0) H(0) \lim _{t \rightarrow \infty} e^{-\left(\sigma\left(1-f\left(\zeta s_{H}\right)\right) t\right.}=0
$$

since $f\left(\zeta s_{H}\right) \in(0,1)$.

From (A9) we have: $\gamma=\frac{\sigma\left(\left[f\left(\zeta s_{H}\right)\right] \theta-1+\varphi\right)}{(1-\varphi) \varphi}+\frac{\rho}{\varphi}$. Since $f\left(\zeta s_{H}\right)$ is an invertible function by assumption, then from (A9) we get:

$$
\begin{gathered}
\frac{(1-\varphi)[\varphi \gamma+\sigma-\rho]}{\sigma \theta}=f\left(\zeta s_{H}\right) \Rightarrow f^{-1}\left[\frac{(1-\varphi)[\varphi \gamma+\sigma-\rho]}{\sigma \theta}\right]=\zeta s_{H} \Rightarrow s_{H}=\frac{f^{-1}\left(\zeta s_{H}\right)}{\zeta} \\
1-s_{H}=s_{Y}=\frac{\zeta-f^{-1}\left(\zeta s_{H}\right)}{\zeta}
\end{gathered}
$$

In order the expression inside the brackets in equation (A10) to be a positive number we need: $\varphi \gamma+\sigma-\rho>0 \Rightarrow<0<\frac{\rho-\sigma}{\varphi}<\gamma$, since $\varphi<0$ and $\sigma-\rho>0$ as it is shown below. Since $1-s_{H}=s_{Y} \in(0,1)$ then we need $\zeta>f^{-1}$. Moreover we have $f^{-1}>0$ since $f^{\prime}>0$ and $\left(f^{-1}\right)^{\prime}>0$ as well since $f\left(\zeta s_{H}\right)$ is invertible.

From equation (A9) by using the result from (A6) we get the following result:

$$
\gamma=\frac{\sigma\left(\left[f\left(\zeta s_{H}\right)\right] \theta-1+\varphi\right)}{(1-\varphi) \varphi}+\frac{\rho}{\varphi}=\frac{\sigma\left[f\left(\zeta s_{H}\right)\right] \theta-\sigma(1-\varphi)}{(1-\varphi) \varphi}+\frac{\rho}{\varphi}=\frac{\gamma \theta}{\varphi}-\frac{\sigma}{\varphi}+\frac{\rho}{\varphi}=\frac{\gamma \theta}{\varphi}+\frac{\rho-\sigma}{\varphi} \text { (A9') }
$$




\section{BOIKOS Corruption, Public Expenditure and Human Capital Accumulation}

We define: $\Psi(\gamma)=\frac{\gamma \theta}{\varphi}+\frac{\rho-\sigma}{\varphi}$, so (A9') becomes $\Omega(\gamma)=\gamma-\Psi(\gamma)$. In order to exist an endogenous solution for $\gamma$, we need either $\left\{\Psi^{\prime}(\gamma)>0\right.$ if $\left.\Psi(0)<1\right\}$ or $\left\{\Psi^{\prime}(\gamma)<0\right.$ if $\left.\Psi(0)>1\right\}$.

Since, from (A8) $\left[\left(1-s_{H}\right)=s_{Y}\right]$ is constant in BGP, then $f\left(\zeta s_{H}\right)$ and $g\left(\delta\left(1-s_{H}\right)\right)$ are constant in BGP as well.

We can show that $\Psi^{\prime}(\gamma)=\frac{\theta}{\varphi}<0$ for $\varphi<0$. Then we need $\Psi(0)>1$. We can show that $\Psi(0)=\frac{\rho-\varphi}{\varphi}>1$ iff $\{\sigma>\rho\}$ and $\{\rho-\varphi>\sigma\}$ which is true since $\varphi<0$ by assumption.

If the above conditions hold then an endogenous growth rate of the economy $\gamma^{*}$ exists in BGP and, if we replace $\gamma^{*}$ inside (A10), there exists an endogenous $\left(1-s_{H}^{*}\right)=s_{Y}^{*}$ which is equal to:

$$
\left(1-s_{H}^{*}\right)=s_{Y}^{*}=\frac{\zeta-f^{-1}\left[\frac{(1-\varphi)[\varphi \gamma+\sigma-\rho]}{\sigma \theta}\right]}{\zeta} \text {. Therefore, } \quad \gamma^{*} \quad \text { and }\left(1-s_{H}^{*}\right)=s_{Y}^{*} \text { are }
$$

determined simultaneously.

\section{Appendix B}

OECD Countries: Australia, Austria, Belgium, Canada, Chile, Czech Republic, Denmark, Finland, France, Greece, Hungary, Iceland, Ireland, Italy, Japan, Mexico, Netherlands, New Zealand, Norway, Poland, Portugal, Republic of Korea, Spain, Sweden, Switzerland, U.K., U.S.

Non-OECD Countries: Algeria, Argentina, Bahrain, Bangladesh, Barbados, Benin, Bolivia, Botswana, Brazil, Bulgaria, Burundi, Cameroon, Central African Republic, Colombia, Costa Rica, Cote d’ Ivoire, Cuba, Cyprus, Dominican Republic, Ecuador, Egypt, El Salvador, Fiji, Ghana, Guatemala, Guyana, Hong Kong, India, Indonesia, Iran (Islamic Republic of), Israel, Jamaica, Kenya, Kuwait, Lao Republic, Latvia, Lesotho, Liberia, Malawi, Malaysia, Mali, Mauritius, Moldova, Morocco, Mozambique, Namibia, Nepal, Nicaragua, Niger, Pakistan, Panama, Paraguay, Peru, Philippines, Romania, Russian Federation, Rwanda, Saudi Arabia, Senegal, Sierra Leone, Singapore, South Africa, Swaziland, Tajikistan, Thailand, Togo, Trinidad and Tobago, Tunisia, United Ar. Emirates, Uganda, Uruguay, Yemen, Zambia. 
Review of Economic Analysis 8 (2016) 17-45

Latin America Countries: Argentina, Barbados, Bolivia, Brazil, Chile, Colombia, Costa Rica, Cuba, Dominican Republic, Ecuador, El Salvador, Guatemala, Guyana, Jamaica, Mexico, Nicaragua, Panama, Paraguay, Peru, Trinidad and Tobago, Uruguay.

Sub-Saharan Africa Countries: Benin, Botswana, Burundi, Cameroon, Central African Republic, Ghana, Cote d' Ivoire, Kenya, Lesotho, Liberia, Malawi, Mali, Mauritius, Mozambique, Namibia, Niger, Senegal, Sierra Leone, South Africa, Swaziland, Togo, Uganda, Zambia.

Transition Countries: Bulgaria, Croatia, Cuba, Czech Republic, Estonia, Hungary, Latvia, Poland, Romania, Russian Federation, Slovak Republic.

\section{References}

Acemoglu, D. and Verdier, T. (1998), Property Rights, Corruption and the Allocation of Talent: A General Equilibrium Approach, Economic Journal, 108, 1381-1403.

Aghion, P. and Howitt, P. (2007), Capital, innovation, and growth accounting, Oxford Review of Economic Policy, 23, 79-93.

Aidt, T., Dutta, J. and Senna, V. (2008), Governance regimes, corruption and growth: theory and evidence, Journal of Comparative Economics, 36, 195-220.

Aidt, T. (2009), Corruption, institutions and economic development, Oxford Review of Economic Policy, 25, 271-291.

Barreto, A. R. (2000), Endogenous corruption in a neoclassical growth model, European Economic Review, 44, 35-60.

Barro, R. J. (1990), Government spending in a simple model of endogenous growth, Journal of Political Economy, 98, 103-125.

Barro, R. J. (1991), Economic growth in a cross section of countries, Quarterly Journal of Economics, 106, 407-433.

Barro, R. J. and Lee, Jong-Wha (2010), International data on educational attainment for total population 1950-2010. September 2011.

Benhabib, J. and Spiegel, M. (1994), The role of human capital in economic development: evidence from aggregate cross-country data, Journal of Monetary Economics, 34, 143174.

Bils, M. and Klenow, P. J. (2000), Does schooling cause growth?, American Economic Review, 90, 1160-1183.

Bjørnskov, C. (2003), Corruption and social capital, Working Papers 03-13, University of Aarhus, Aarhus School of Business, Department of Economics.

Been-Lon Chen (2003), Tax evasion in a model of endogenous growth, Review of Economic Dynamics, 6, 381-403. 


\section{BOIKOS Corruption, Public Expenditure and Human Capital Accumulation}

Blackburn, K., Bose, N. and Emranul Haque, M. (2006), The incidence and persistence of corruption in economic development, Journal of Economic Dynamics and Control, 30, 2447-2460.

Blackburn, K., Bose, N. and Emranul Haque, M. (2011), Public expenditures, bureaucratic corruption and economic development, Manchester School, University of Manchester, 79, 405-428.

Campos, F. N., Dimova R. and Saleh, A. (2010), Whither corruption?, A quantitative survey of the literature on corruption and growth, Discussion Paper no.8140, Centre of Economic Policy Research.

Davidson, R. and Mackinnon, J. G. (1993), Estimation and inference in econometrics. New York: Oxford University Press.

De la Fuente, A. and Domenech, R. (2006), Human capital in growth regression: how much difference does data quality make?, Journal of the European Economic Association, MIT Press, 4, 1-36.

Devarajan, S., Swaroop, V. and Zou, Heng-fu (1996), The composition of public expenditure and economic growth, Journal of Monetary Economics, 37, 313-344.

Ebben, W. and de Vaal, A. (2011), Institutions and the relation between corruption and economic growth, Review of Development Economics, 15, 108-123.

Ehrlich, I., A. and Lui, F. T. (1999), Bureaucratic corruption and endogenous economic growth, Journal of Political Economy, 107, Part 2: Symposium on the Economic Analysis of Social Behavior in Honor of Gary Becker. (Dec. 1999), pp.S270-S293.

Fan, J. (1992), The design-adaptive nonparametric regression, Journal of the American Statistical Association, 87, 998-1004.

Fan, J. and Zhang, W. (1999), Statistical estimation in varying coefficient models, The Annals of Statistics, 27, 1491-1518.

Fisman R. and Svensson, J. (2007), Are corruption and taxation really harmful to growth? Firm level evidence, Journal of Development Economics, 83, 63-75.

Ghosh, S. and Gregoriou, A. (2008), The composition of government spending and growth: is current or capital spending better?, Oxford Economic Papers, 60, 484-516.

Glomm, G. and Kaganovich, M. (2003), Distributional effects of public education in an economy with public pensions, International Economic Review, 44, 917-937.

Gordon, R. and Li, W. (2009), Tax structures in developing countries: many puzzles and a possible explanation, Journal of Public Economics, 93, 855-866.

Gozalo, P. and Linton, O. (2000), Local nonlinear least squares estimation: using parametric information non-parametrically, Journal of Econometrics, 99, 63-106.

Gupta, S., Davoodi, H. and Tiongson, E. (2000), Corruption and the provision of health care and education services, IMF Working Paper, WP/00/116. 
Heston, A., Summers, R. and Aten, B. Penn World Table Version 7.0, Center of International Comparisons of Production, Income and Prices at the University of Pennsylvania, May 2011.

Hsiao C., Li, Q. and Racine, J.S. (2007), A consistent model specification test with mixed categorical and continuous data, Journal of Econometrics, 140, 802-826.

Huntigton, S. P. (1968), Political order in changing societies. New Haven: Yale University Press.

Islam, N. (1995), Growth empirics: a panel data approach, Quarterly Journal of Economics, 110, 1127-1170.

Johnson, S., Kaufmann, D. and Pablo Zoido-Lobaton (1999), Corruption, public finances and the unofficial, World Bank Discussion Paper Series no. 2169 (Washington: World Bank).

Kalaitzidakis, P., Mamuneas, T., Savvides, A. and Thanasis Stengos (2001), Measures of human capital and nonlinearities in economic growth, Journal of Economic Growth, 6, 229-254.

Kaufmann, D., Kraay, A. and Mastruzzi, M. (2010), The worldwide governance indicators: a summary of methodology, data and analytical issues, World Bank Policy Research Working Paper no. 5430.

Lau, L.J., Jamison, D.T. and Louat, F.F. (1991), Educational productivity in developing countries: an aggregate production function approach, World Bank Policy Research Working Paper no.612.

Leff, N. (1964), Economic development through bureaucratic corruption, American Behavioral Scientist, 82, 337-341.

Li, Q., Huang, C., Li, D. and Fu, T. (2002), Semiparametric smooth coefficient models. Journal of Business and Economic Statistics, 20, 412-422.

Lin, S. (1998), Government education spending and human capital formation, Economics Letters, 61, 391-393.

Litina, A. and Theodore Palivos (2011), Explicating corruption and tax evasion: reflections on Greek tragedy, Discussion Paper no.07/2011, ISSN 1791-3144.

Lucas, R.E. (1988), On the mechanics of economic development, Journal of Monetary Economics, 22, 3-42.

Mamuneas, P.M., Savvides, A. and Thanasis Stengos (2006), Economic development and the return to human capital: a smooth coefficient semiparametric approach, Journal of Applied Econometrics, 21, 111-132.

Mankiw, N.G., Romer, D. and Weil, D.N. (1992), A contribution to the empirics of economic growth, Quarterly Journal of Economics, 107, 407-437.

Mauro, P. (1995), Corruption and growth, Quarterly Journal of Economics, 110, 681-712.

Mauro, P. (2004), The persistence of corruption and slow economic growth, IMF Staff Papers, 51, no.1, 2004 International Monetary Fund. 
BOIKOS Corruption, Public Expenditure and Human Capital Accumulation

McAdam, P. and Rummel, O. (2004), Corruption: a non-parametric analysis, Journal of Economic Studies, 31, 509-523.

Mironov, M. (2005), Bad corruption, good corruption and growth, Working Paper, University of Chicago.

Mo, P. H. (2001), Corruption and economic growth, Journal of Comparative Economics, 29, 66-79.

Murphy, K. M., Sleifer, A. and Vishny, R. W. (1991), Corruption, Quarterly Journal of Economics, 106, 599-617.

Murphy, K. M. and Vishny, R. W. (1993), The allocation of talent: implications for growth, Quarterly Journal of Economics, 108, 503-530.

Pecorino, P. (1992), Rent seeking and growth: the case of growth through human capital accumulation, Canadian Journal of Economics, 25, 944-956.

Rajkumar S., Swaroop, A. V. (2008), Public spending and outcomes: does governance matter?, Journal of Development Economics, 86, 96-111.

Rogers, M. (2008), Directly unproductive schooling: how country characteristics affect the impact of schooling on growth, European Economic Review, 52, 356-385.

Sarte Pierre-Daniel (2000), Informality and rent-seeking bureaucracies in a model of long-run growth, Journal of Monetary Economics, 46, 173-197.

Silverman, B. W. (1986), Local density estimation for statistics and data analysis. New York: Chapman and Hall.

Stone, C. J. (1977), Consistent non-parametric regression, Annals of Statistics, 5, 595-620.

Svensson, J. (2005), Eight questions about corruption, Journal of Economic Perspectives, 19, 19-42.

Tanzi, V. and Davoodi, H. (1997), Corruption public investment and growth, IMF Working Paper no. 97/139. Washington DC.:IMF.

United Nations, Educational, Scientific and Cultural Organization (UNESCO) Institute for Statistics. World Development Indicators. (2010).

United Nations, Department of Economic and Social Affairs, Population Division, World Population Prospects: The 2010 Revision, New York, 2011. 